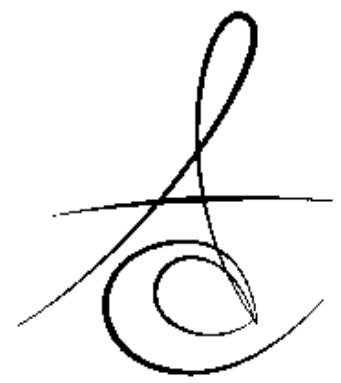

\title{
SÜT DİŞLERİNDE NİKEL TİTANYUM DÖNER ALETLERİNİN KULLANIMININ DEĞERLENDİRİLMESİ
}

EVALUATION OF THE USE OF NICKEL TITANIUM ROTARY INSTRUMENTS IN PRIMARY TEETH

Arş.Gör.Dt. Gökçe GARİP*

Yrd. Doç. Dr. Mustafa ALTUNSOY*
Yrd. Doç. Dr. Bilge Gülsüm NUR*

Yrd. Doç. Dr. Evren OK ${ }^{* *}$

Makale Kodu/Article code: 1754

Makale Gönderilme tarihi: 26.06 .2014

Kabul Tarihi: 13.10 .2014

\section{ÖZET}

Endodontik tedavi çocuk diş hekimliği uygulamalarının büyük bir kısmını oluşturmakta ve el ile enstrümantasyondan döner alet sistemlerinin kullanımına doğru zamanla geçiş göstermektedir. Süt dişlerinde el aleti ile yapılan tedavilerdeki en büyük endişe, özellikle küçük ve kooperasyonu güç çocuklarda artmış kök kanal preparasyon zamanı olmaktadır. Bununla ilgili olarak; nikel titanyum döner aletlerin endodonti pratiğinde uygulanmaya başlanmasının ardından kök kanal tedavisi daha basit, hızlı ve güvenli hale gelmiştir. Özellikle döner aletler; daimi azı dişlerin eğri kanallarında; düşük flare-up riski ve artmış hasta konforuyla beraber zamandan tasarruf sağlamaktadır. Süt dişlerinde döner alet sistemiyle preparasyon ise ilk Profile sistemiyle denenmiş ve daha sonra Protaper, K3 ve Hero Shaper sistemleri kullanılmıştır. Bu sistemlerin düşük elastik modülleri sayesinde dar süt kanallarına girmeleri kolaylaşmakta, kanalların orijinal morfolojisi korunabilmektedir. Aynı zamanda pürüzsüz bir yüzey ile konik kanal formu elde edilebilmektedir. Bunun yanında; çalışma teknikleri oldukça hassas olmakla beraber yanlış uygulandığında alet kırıkları görülme riski artmaktadır. Döner aletler el aletlerine göre pahalı sistemlerdir. Nikel titanyum döner alet sistemleriyle ilgili daimi dişlerde fazla sayıda çalışma yapılmasına karşın, süt dişlerinde çalışma sayısı oldukça azdır. Bu derlemede gününüze kadar kullanılmış ve kullanılmakta olan çok eğe sistemli ve tek eğe sistemli Nikel Titanyum döner aletleri gözden geçirilmiştir.

Anahtar kelimeler: Süt dişleri, Kök kanal tedavisi, Titanyum nikelid

\section{ABSTRACT}

Endodontic treatment is one of the major part of pediatric dentistry and recently shows alteration from hand instrumentation to rotary instruments. The major concern of hand instrumentation in primary teeth is increased root canal preparation time in young children with limited cooperation. Since the introduction of rotay instruments in endodontic treatment, root canal treatment has become more simple, more secure and fast. Especially in curved canals of molar teeth, rotary instruments reduce time with increased patient comfort and lower risk of flare-up. Root canal preparation of primary teeth was first tried with Profile and then; Protaper, Hero Shaper and K3 rotary files were used. Because of low modulus of elasticity; it can be easy to preparate narrow primary canals and protect original root canal morfology. At the same time smooth surface and conic root form can be obtained. In addition rotary instruments need highly sensitive techniques and have a increased fracture risk due to the wrong application. They are also expensive according to hand instrumentation systems. Although there are many studies in permanent teeth about nickel titanium rotary files, there is a little study in primary teeth. In the present review, we evaluated single file and multiple files of the nickel titanium rotary instruments is being used until today.

Key words: Deciduous teeth, Root canal therapy, Nickel titanium rotary files

*Şifa Üniversitesi, Diş Hekimliği Fakültesi, Pedodonti Anabilim Dal

** Şifa Üniversitesi, Diş Hekimliği Fakültesi, Endodonti Anabilim Dalı 


\section{GİRİŞ}

Süt dişlerinde meydana gelen çürükler anatomik yapılarındaki farklııklardan dolayı hızla ilerleyerek önce pulpitis, ardından nekrozla sonuçlanır. ${ }^{1}$ Pulpitis ve nekroz aşamasına gelmiş süt dişlerine kanal tedavisi uygulanmalıdır. ${ }^{2}$ Kanal tedavisi uygulaması; süt dişinin normal düşme zamanına kadar ağızda muhafaza edilmesi, fonasyon ve estetiğin sağlanması gibi avantajlar sağlamaktadır. ${ }^{3,4}$ Süt dişi kök kanal tedavisindeki hedef; kanal aletleri ile kök kanal sisteminin şekillendirilerek enfekte materyalin ve kontamine dentinin büyük bir çoğunluğunun uzaklaştırıması, kök kanalının etkin dezenfeksiyonu ve sızdırmaz bir şekilde doldurulmasıdır. ${ }^{5,6}$

Süt dişlerine uygulanan endodontik tedavilerin başarısı, kemomekanik preparasyon sonucu görülen mikrobiyal azalma ile yakından ilişkilidir. ${ }^{7}$ Enterococcus faecalis gibi mikroorganizmaların konvansiyonel kanal tedavisine gösterdiği direnç tedavideki başarısızlıkların önemli nedeni olmaktadır. ${ }^{8}$

Furkasyondaki aksesuar kanallar ve atipik kök rezorbsiyonu kanalların temizlenme etkinliğini azaltmaktadır. ${ }^{9}$ Süt dişi kanal boylarının kısa olması, aksesuar kanalların fazla sayıda bulunması, kanalların diverjan ve eğri seyretmesi, kök kanal duvarlarının ince olması, dentin dokusunun daha kolay aşındırılabilmesi gibi kök kanal anatomisindeki farklılıklar ve fizyolojik kök rezorbsiyonu gibi durumlar süt dişi kök kanal tedavisini zorlaştırmaktadır. ${ }^{10}$ Ayrıca çocuk hastalarda kooperasyon güçlüğü nedeniyle seans süresinin uzaması, süt dişi kanalının daimi dişlere göre varyasyonlar göstermesi, kök kanal tedavisini güçleştiren diğer faktörler arasında yer almaktadır. ${ }^{11,12}$

Kök kanal tedavisinde kullanılan kanal aletleri ilk olarak 1960 yllında karbon çelik olarak üretilmiş daha sonra yerini paslanmaz çelik alaşımlara bırakmıştır. ${ }^{11}$ Geleneksel paslanmaz çelik kök kanal aletleri elle kullanım için üretilmiş olup tasarımlarına göre üç ayrı tipten oluşur. Bunlar; reamer, K-tipi ve Hedström eğeleridir. Üçgen kesitli reamer eğeler, çelik bir telin kendi ekseni etrafında burulmasıyla üretilmiş mekanik özelliği zayıf eğelerdir. Bunlar döndürülerek kullanılırlar. K-tipi eğeler; iyi kesme yeteneği olan, esnekliği yüksek eğelerdir ve kanaldan dışarı çekme hareketiyle kullanııılar. Hedström eğeler ise çekirdek çapı küçük, metalin frezleme işlemiyle zayıflatıldığı eğelerdir. Aletin pozitif geri çekme açısına sahip bıçakları, geri çekme esnasında aktiftirler. ${ }^{13}$
Kök kanal tedavilerinde kullanılan paslanmaz çelik el aletleri, esnekliklerinin az olması nedeniyle, özellikle eğri kanallarda istenmeyen kanal şekillerinin oluşmasına ve perforasyonlara neden olabilmektedir. ${ }^{14} \mathrm{Bu}$ olumsuzluklar nedeniyle; öncelikle el ile kullanılabilen, esnek nikel titanyum kanal aletleri piyasaya sürülmüştür. Fakat bu aletlerin dentini kesme etkinliklerinin yeterli ölçüde olmaması nedeniyle çalışma süresinde kısalma sağlanamamıştır. ${ }^{15}$ Bu problemin üstesinden gelebilmek için redüksiyonlu anglduruva ile sabit devirde kullanılabilen, yüksek esnekliğe sahip olan $\mathrm{Ni}-\mathrm{Ti}$ (nikel titanyum) döner alet sistemleri geliştirilmiştir. ${ }^{11}$

Buehler tarafından 1960 yılında üretilen $\mathrm{Ni}-\mathrm{Ti}$ alaşımlar \% 56 nikel, \% 44 titanyumdan oluşmaktadır. Ayrıca düşük elastiklik modülü $\left(35 \mathrm{KN} / \mathrm{mm}^{2}\right)$ ve şekil hafızası gibi avantajlı özelliklere sahiptir. ${ }^{13}$ Yüksek açוlı endodontik aletler olarak da tanımlanan döner Ni-Ti eğeler; \% 2-12 arasında değişen taper'larda dizayn edilmiştir. Bu sayede kanalın en dar yerinden koronale doğru gittikçe açılan huni şeklinde kanal formu elde edilebilmektedir.

$\mathrm{Ni}$-Ti alaşımların gelişimleri, değişik varyasyonlarda dizayn ve taper'lara sahip olmalarl; son zamanlarda bu sistemlerin endodonti pratiğinde sıklıkla kullanımına olanak sağlamışıı. ${ }^{16} \mathrm{El}$ aleti ile preparasyon tekniğinin zaman alıcı olması ve iyatrojenik perforasyonlara neden olabilmesi sonucu, dikkatler $\mathrm{Ni}-\mathrm{Ti}$ döner aletleriyle kök kanal preparasyonu üzerine yoğunlaşmışıı. ${ }^{17} \mathrm{Bu}$ derlemede gününüze kadar kullanılmış ve kullanılmakta olan çok eğe sistemli ve tek eğe sistemli Nikel-Titanyum döner aletler gözden geçirilmiştir.

Başlıca Döner Alet Sistemleri ve Süt

\section{Dişlerinde Kullanımları}

Nikel titanyum döner aletlerin süt dişlerinde kullanımıyla ilgili bazı çalışmalar yapılmış olsa da; ${ }^{11,16,18-20}$ araştırmacıların çoğu bunların daimi dişlerde etkinliği konusunda yoğunlaşmışır. ${ }^{21-24}$

$\mathrm{Bu}$ aletler ile süt dişlerinin etkili kök kanal temizliğinin kısa sürede yapılabileceği ilk olarak Barrr ${ }^{25}$ tarafından bildirilmiştir. Nikel titanyum döner aletlerle yapılan çalışmalarda; pürüzsüz bir yüzey, konik kanal formu ve minimal transportasyon (hatalı eğeleme sonucu kanalın apikal kısmının yer değiştirmesi) riski olduğu belirtilmiştir. ${ }^{26-29}$ Kanal anatomisine zarar vermeden kök kanalında kendi ekseni etrafında dönebilme yetenekleri ve elastik hafızaları önemli

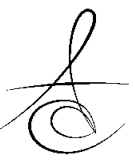


avantajları arasında yer almaktadır. ${ }^{16}$ Düşük elastiklik modülleri sayesinde dar süt kanallarına girmeleri kolaylaşmakta ve orijinal kök kanal formu muhafaza edilebilmektedir. ${ }^{7,19,30}$ Bunun yanında motor ile aktive olduklarından dolayı daha hızı kök kanal preparasyonu elde edilebilmektedir. ${ }^{16}$

Nikel titanyum döner aletleri sahip oldukları yüksek elastisite özelliklerine rağmen; aletlerin kurvatürlü kanal bölgelerinde karşılaştıkları gerilme ve sıkışma stresleri, metal yüzeyinden taneciklerin kopmasına ve çatlakların yavaş yavaş yayılmasına neden olabilmektedir. ${ }^{18}$ İçsel defektlerin birikimi ile düşük streslerde bükülme kırıkları meydana gelebilmektedir. Fleksürel kırılmalar; eğri kanallarda çalışırken, kanal duvarı ile sürekli temas sonucu olan döngüsel yorgunluk ve uygulanan tork nedeniyle olabilmektedir. ${ }^{31}$ Aletin kök kanalına sıkışması sonucu da kırıklar gerçekleşebilmektedir. Bu durum özellikle kesici bıçakları yıpranmış aletin, kanal duvarına saplanmasının ardından rotasyona zorlanmasını takiben ortaya çıkabilmekte ve buna torsiyonel kırık denilmektedir. ${ }^{32}$ Diğer dezavantaj ise Ni-Ti aletlerin pahalı olmalarıdır. Bunun yanında hekim çalışırken oldukça titiz davranmalıdır. Olası kırıkları önlemek için kök kanal anatomisi iyi bilinmeli ve çalışırken alete gereğinden fazla basınç uygulanmamalıdır. ${ }^{25}$

Nagaratna ve arkadaşlar ${ }^{11} 20$ adet mandibular ikinci süt azı dişi ve 20 adet mandibular birinci daimi azı dişi kullanarak gerçekleştirdikleri çalışmalarında; NiTi döner aletleri ile K-file el aletinin etkinliğini ve çalışma zamanını kıyaslamışlardır. Gruplar ikiye ayrılarak Kfile ve Ni-Ti döner alet ile preparasyon yapılmıştır. Araştırmanın sonucunda, döner aletle çalışırken ihtiyaç duyulan zaman K-file el aletine göre oldukça kısa bulunmuştur. ${ }^{16,25}$ Nikel Titanyum döner alet sistemlerinde tek eğe ile kanal preparasyonu bitirilebilirken, bazı sistemlerde ise birden fazla eğe kullanılmaktadır.

\section{Aletleri}

Çok Eğe Sistemli Nikel Titanyum Döner

\section{Hero 642}

Bu sistemde dakikada 300-600 devir hızla çalışan, saat yönünde tam rotasyon yapan, özel mikromotor angldruvaları ile eğeler kullanılmaktadır. ${ }^{33}$ Hero 642 döner alet sisteminin az sayıda alet içermesi ve kolay uygulanabilir olması tedavide pratiklik sağlamaktadır. Aletlerin konikliklerinin azlığı ve yüksek elastikiyetleri; alet kırığı riskini belirgin ölçüde azaltmaktadır. Hero 642 sistemi kanal transportasyonu ve perforasyonuna neden olmaması nedeniyle hem süt hem de daimi dişlerde güvenli ve etkili bir şekilde kullanılabilmektedir ve süt dişlerinde kök kanal tedavisinde $\mathrm{K}$ tipi eğelere tercih edilmektedirler. ${ }^{7}$

Arıkan ve ark ${ }^{34} 54$ süt azı dişinde gerçekleştirdikleri çalışmalarında; Hero 642, Protaper ve K tipi eğeleri perforasyon, alet kırı̆̆ı ve preparasyon süresi bakımından karşılaştırmışlardır. Gruplar arasında prepare edilen toplam kanal tipi ve kanal sayısına göre alet kırığı ve perforasyon açısından belirgin fark bulunmamıştır. Preparasyon süreleri açısından en kısa süre Hero 642, en uzun süre ise $K$ tipi eğede gözlenmiştir. Çalışma sonucunda Hero 642; hem kullanım güvenilirliği ve hem de çalışma süresi açısından süt dişlerinde başarılı sonuçlar göstermiştir. Hülsmann ve ark $^{35}$ Hero 642 ve Quantec döner alet sistemlerini daimi dişlerde karşılaştırdıkları çalışmalarında; Quantec ve Hero 642'nin kanal kurvatürünü koruduğu, kaldırılan debris miktarının Hero 642'de ise daha fazla olduğunu bildirmişlerdir.

\section{Profile}

Profile sistemi; kesici olmayan bir uç ve radyal alan olmak üzere iki önemli özelliğe sahiptir. Üretici tarafından süt kanallarında kullanılmak üzere daha az agresif olarak tasarlanmıştır. Profile koronal yönde kök kanalından debrisi kaldırmaya yardımcı olup; kanal aletini çalışma esnasında merkezde tutarak apikal perforasyonları önlemektedir. ${ }^{16}$

$\mathrm{Bu}$ sistemle kanallar uygun koniklikte ve pürüzsüzlükte hızlı bir şekilde şekillendirilmekte, fakat spirallerin sıkışması nedeniyle alet kırıkları oluşabilmektedir. ${ }^{11}$ Bu nedenle süt kök kanallarının temizlenmesi ve şekillendirilmesi için Profile aletinin 150-300 rpm hızında çalıştırılması tavsiye edilmektedir. ${ }^{36}$

Pettiette ve $\mathrm{ark}^{37}$ Profile sisteminin crowndown tekniği ile kullanılmasını önerirken; Barr ve $\mathrm{ark}^{25}$ süt dişlerinde dentinin kaldırılmasının daha kolay olmasından dolayı, bu tekniği gerekli görmemektedir. Silva ve ark ${ }^{16}$ Profile ve $\mathrm{K}$ tipi eğeyi karşılaştırdıkları çalışmalarında step-back tekniğini uygulayarak bu görüşü desteklemiştir. Bununla beraber Profile ve $\mathrm{K}$ tipi eğenin etkinliklerinin karşılaştırıması konusunda yapılan çalışmalarda gruplar arasında kök kanalı şekillendirme etkinliği açısından fark görülmemiştir. ${ }^{16,38}$ Ayrıca Profile ile preparasyonun daha çabuk tamamlandığı, daha konik kanal formu oluşturduğu ve etkili bir kanal dolgusuna olanak sağladığı görülmüştür. ${ }^{11,16,39}$

\section{Hero Shaper}

Hero 642 eğelerinden daha esnek olan Hero

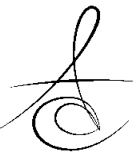


Shaper döner alet sistemiyle ilgili Kaptan ve $\operatorname{ark}^{40}$ yaptığı çalışmada; 60 adet alt çene santral diş kullanılmıştır. Dişler üç gruba ayrılarak Hero Shaper, Protaper ve Profile ile şekillendirilmiş ve apikalden kaldırılan debris miktarı değerlendirilmiştir. Çalışma sonucunda Hero Shaper ile Protaper'ın benzer miktarlarda; Protaper'ın ise Profile'den daha yüksek miktarda debris kaldırdığı belirlenmiştir. Musale ve ark ${ }^{41}$ Hero Shaper'ın süt dişlerinde etkinliğini incelemişlerdir. Bu çalışmada 60 adet çekilmiş süt azı dişini dört eşit gruba bölerek; Protaper, Profile, Hero Shaper ve K-tipi eğe ile dişlerde genişletme sağlamışlardır. Temizleme etkinlikleri, şekillendirme performansları, çalışma zamanı ve aletlerdeki distorsiyon durumlarını karşılaştırmışlardır. Çalışmalarının sonucunda döner aletlerin, K-tipi eğelere oranla daha konik kanal formu sağlayabildiğini, K-tipi eğenin ortalama çalışma zamanının döner aletlere oranla daha fazla olduğunu bulgulamışlardır.Ayrıca K-tipi eğede distorsiyon gözlenirken, döner aletlerde gözlenmemiştir.

\section{Mtwo}

2003 yılında üretilen Mtwo; 10 ile 25 numara arasında değişen ölçülerde ve farklı taperłarda dört çeşit uç içermektedir. Üretici firma erken koronal geniş- letme yapılmadan, minimal invaziv yaklaşımla ve sabit boyda çalışılmasını tavsiye etmektedir. ${ }^{42-44} \mathrm{Bu}$ durum tekniği daha basit hale getirmektedir. Bu sistemde step-back tekniğinde olduğu gibi küçük aletler büyük aletlerden önce kullanılmaktadır.

Mtwo aletlerinin özel dizaynları ve yüksek esneklik kabiliyetleri orijinal kanal kurvatürünün devamlıı̆ını sağlamaktadır. Ayrıca bu aletlerin pozitif rake açıları ile etkili, güvenli ve kısa zamanda kanalların temizliği gerçekleşmektedir. Kesme etkinlikleri, çalışma boyunu ve kanal kurvatürünü korumaları diğer döner aletlerden üstün özellikleri arasındadır. ${ }^{42,43}$ Araştırmalarda kanal formunu K3, Race ve Protaper aletlerinden daha iyi koruduğu görülmüştür. ${ }^{45}$

Mohammed Azar ve $\operatorname{ark}^{46} 70$ adet süt ve 70 adet daimi azı dişi kullanarak gerçekleştirdikleri çalışmalarında, Mtwo ve $\mathrm{K}$ tipi eğelerinin temizleme etkinliklerini ve çalışma sürelerini değerlendirmişlerdir. Araştırmalarının sonucunda; daimi ve süt dişleri kanallarında apikal, orta ve koronal üçlü bölgesinde temizleme etkinliği açısından fark gözlenmemiştir. Mtwo grubunda çalışma süresinin el aletine oranla daha kısa olduğu kaydedilmiştir.

\section{FlexMaster}

FlexMaster sistemindeki aletler yuvarlak pasif uç ve modifiye çapraz kesite sahiptirler. Radyal alan içermeyen kesici bıçak alanları ile $\mathrm{K}$ tipi eğeye benzemektedirler. ${ }^{17}$ Aletin kesici olmayan ucu ve diş bükey üçgen kesiti çalışırken aletin merkezi konumda kalmasını sağlar. Flex Master eğeler, üzerinde daha az stres oluştuğundan sekiz kez kullanılabilir. Bıçaklar arasındaki yeterli mesafe sayesinde dentin talaşları ve debrisin atılması kolaylaşır. ${ }^{47,48} \mathrm{Bu}$ sistem ile ilgili Moghaddam ve ark $^{17}$ gerçekleştirdikleri çalışmalarında; 60 adet çekilmiş süt azı dişini; K tipi el aleti, Flex Master döner aleti ve kontrol grubu olmak üzere üç gruba ayırarak değerlendirmişler. Flex Master ile ortalama çalışma süresinin K tipi eğeye göre oldukça kısaldığı gözlenmiştir. Ayrıca apikal ve orta üçlüde Flex Master ile başarılı sonuçlar elde edilirken, koronal üçlüde $\mathrm{K}$ tipi eğe daha başarılı bulunmuştur.

\section{K3}

McSpadden $^{49}$ tarafından geliştirilen bu sistemde aletin 200-300 devir/dakika'da kullanılması tavsiye edilmektedir. Nötre yakın pozitif rake açısına (eğenin uzun eksenine dik olacak şekilde yatay kesiti alındığında, kesici kenarın eğenin yarıçapı ile yaptığı açı) sahip olması, kesme etkinliğini arttırmaktadır. Değişken sarmal yapısı kanal duvarına saplanmayı engellemekte ve debrisin kaldırımasını sağlamaktadır. Aynı zamanda güvenli sonlanan bir uç tasarımına sahiptir. ${ }^{49}$ Kum ve ark $^{50}$ gerçekleştirdikleri çalışmalarında 40 adet alt çene büyük azı dişini K3 ve Profile ile genişletmişlerdir. Araştırmalarında genişletilen mezyal kanalın apikal üçlüsündeki smear tabakasını değerlendirmişlerdir. Sonuç olarak K3 sisteminin daha az smear tabakası oluşturduğunu gözlemlemişlerdir. Gonzalez-Rodrguez ve $\operatorname{ark}^{51} 30$ adet alt çene azı dişinin mezyal kökünü Profile, Hero 642 ve K3 ile genişleterek karşılaştırmalı olarak değerlendirmişlerdir. Sonuç olarak her üç sistemin de kanal kurvatürünü koruduğunu; Hero 642'nin, Profile ve K3'ten daha fazla dentin kaldırdığını gözlemlemişlerdir. Ayrıca K3 sisteminin süt dişinde kullanımıyla ilgili literatürde çalışma bulunmamaktadır.

\section{RaCe}

Keskin kesici ağza sahip bu eğenin kesitleri üçgendir. Sadece 0,02 taper 20 no'lu eğenin kesiti karedir. Keskin kesici ağızları ile dentini minik parçalar halinde kopararak, etkili şekilde keserler. ${ }^{52}$ Schirrmeister ve ark $^{53} 150$ daimi kök kanalında RaCe, FlexMaster, Profile, Sistem GT, Protaper ve Hedström eğelerini karşılaştırmışlardır. Genişletme tamamlandıktan sonra bilgisayar programıla prepare edilmemiş alanlar boyalı olarak belirlenmiştir. Sonuç olarak

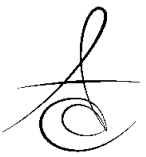


boyanmamış alanların en az RaCe ile prepare edilen kanallarda, ardından Protaper'da olduğu gözlemlenmiştir. Profile ile genişletilen kanallarda ise Sistem GT, FlexMaster ve Protaper'dan daha fazla boyalı alan belirlenmiştir. Bu sistem ile literatürde süt dişlerinde yapılmış bir çalışma bulunmamaktadır.

\section{Protaper}

Protaper döner alet sistemi; saat yönünde tam tur rotasyon yapan özel mikromotor angldurva ve konveks üçgensel bir kesite sahip döner aletlerden oluşmaktadır. ${ }^{54}$ Aletlerin pozitif rake açısı ve kesici olmayan bir uç şekli vardır. ${ }^{55} \mathrm{Bu}$ dizayn alet bıçaklarının kanal duvarına temasını arttırmakta ve kök ucu yönünde konikleşen düz bir yüzey elde edilmesini sağlamaktadır. ${ }^{22,55} \mathrm{Bu}$ sistem; girişte kullanılmak üzere bir eğe (SX), şekillendirmek için iki eğe $(S 1, S 2)$ ve beş tane bitirme eğsinden (F1-F5) oluşmaktadır. Aletler crown-down tekniği için dizayn edilmiş değişken taperłı gövdelere sahiptir. Bu sistemle çalışırken büyük taperłı aletlerin küçük taperłı aletlerden önce kullanıdığı, kanalların koronalden apikale doğru prepare edildiği crown-down tekniğinin kullanımı önerilmektedir. 22,55-57

Protaper sisteminin değişken taper yapısı aletlerin kesme etkinliğini arttırırken bükülme direncini de arttırmaktadır. Özellikle son aletlerin uç kısmındaki bükülme direnci eğimli kanallarda yüksek lateral kuvvetlere neden olabilmektedir. Bu durum süt dişlerinin ince dentin duvarlarında fazla miktarda dentin kaldırılmasına ve perforasyonlara yol açabilmektedir. Perforasyonların daha çok F2 ve F3 eğelerinde görülmesi bu görüşü desteklemektedir. ${ }^{52}$ GT Rotary, Quantec ve Profile ile plastik bloklarda kıyaslanan Protaper marka enstrümanlar daha kısa zamanda daha fazla dentin dokusunu kaldırarak herhangi bir sapma olmadan genişletme yapabilmektedir. ${ }^{58}$

Protaper'ın diğer sistemlere göre sertliğinin fazla olması azalmış kanal kurvatürü, artmış apikal transportasyon ve apikalde basamak oluşumu gibi durumlara neden olabilmektedir. Yoshimine ve ark ${ }^{59}$ Protaper, K3 ve Race döner alet sistemlerini karşılaştırdıkları çalışmalarında; Protaper sisteminin daha fazla dentin kaldırdığını, daha az taperıı ve daha esnek olan K3 ve Race sistemlerinin kurvatürlü kanallarda tercih edilebileceğini bildirmişlerdir. Kuo ve arkadaş- ları ${ }^{60}$ ise; Protaper aletlerinin süt dişlerinde güvenli ve etkili bir şekilde kök kanal tedavisinde kullanılabile- ceğini gözlemlemişlerdir.

\section{Tek Eğe Sistemli Nikel Titanyum Döner} A/etleri

Tek eğe ile kanal preparasyonu konsepti, ilk olarak Yared tarafından tanıtılmıştır. ${ }^{61} \mathrm{Bu}$ sistemlerden One Shape devamlı rotasyon hareketiyle çalışırken; Dentsply tarafından geliştirilen yüksek taper łı Reciproc döner alet sistemi resiprokasyon (kök kanalı içerisinde gerçekleştirilen çeyrek turluk dönüşler) hareketiyle, Wave One ise saat yönünde ve saat yönünün tersi yönde hareket ile çalışmaktadır. Bunlar kanalların tek eğe ile tamamlamasına izin veren yenilikçi sistemlerdir. ${ }^{62,63}$

\section{Wave One}

Wave One döner alet sistemi kanalın genişliğine bakılarak seçilmek üzere 3 farklı boyutta, tek kullanımlık eğe içermektedir. ${ }^{64}$ Wave One döner eğe sisteminde kanallar tek eğe ile şekillendirilmektedir. Tek eğe ile kök kanalının genişletilebilmesi, hekime zamandan tasarruf ve irigasyon tekniklerine daha fazla zaman ayrılabilmesi gibi avantajlar sağlamaktadır. Ayrıca eğelerin tek kullanımlık olması çapraz enfeksiyon riskini ve uygulama hatalarını elimine etmektedir. ${ }^{65}$ Sahip oldukları fiziksel özellikleri aletin döngüsel yorgunluk eşiğinin, konvansiyonel $\mathrm{Ni}-\mathrm{Ti}$ aletlere oranla \%400 daha fazla yükselmesini sağlamaktadır. ${ }^{64}$ Yoo ve ark $^{66}$ rezin bloklarda yaptıkları çalışmada; eğri kanallara sahip toplam 25 adet çekilmiş daimi dişi beş gruba ayırarak, Wave One, Reciproc, Protaper, Profile ve K-tipi eğelerle ile kanalları şekillendirmişlerdir. Tedavi öncesi ve sonrası görüntüleri mikroskopta inceleyerek kaldırılan rezin miktarı ve şekillendirme etkinliklerini değerlendirmişlerdir. Çalışma sonucunda her alet için farklı boylarda farklı miktarlarda rezin kaldırıldığını gözlemişlerdir. Reciproc ve Wave One sistemlerin eğri kanallarda kök kanal formunun devamlıı̆ını, Profile ve K-tipi eğeden daha iyi sağladığını belirtmişlerdir. Literatürde süt dişlerinde Wave One sisteminin kullanımıyla ilgili bir çalışma bulunmamaktadır.

\section{One Shape}

One Shape döner alet sistemi; kaliteli kök kanal temizliği için devamlı rotasyon yaparak çalışmakla beraber eğri kanallarda rahatlıkla kullanımı tavsiye edilmektedir. ${ }^{67} \mathrm{Bu}$ sistemde kanal eğesinin pasif uç yapısı sayesinde herhangi bir engel oluşturmadan, etkili apikal devamlıık sağlanabilmektedir. Dikkat çekici dizayna sahip tek eğe sistemi ile kaliteli bir şekillendirme elde edilebilmektedir. One Shape sistemi ile yapılan kök kanal tedavisi, konvansiyonel 
sistemlere göre yaklaşık olarak dört kat hızı tamamlanabilmektedir. ${ }^{65}$ Anil ve ark $^{67}$ çalışmalarında One Shape ve Wave One tek eğe sistemli döner aletlerini karşılaştırmışlardır. Çalışmalarının sonucunda resiprokasyon hareketiyle çalışan Wave One döner aletinin, rotas- yonla çalışan One Shape döner aletine oranla kök kanal anatomisini daha iyi koruduğunu ve kanal kurvatüründe daha az bozulmaya neden olduğunu bildirmişlerdir. Bu sistemle ilgili literatürde süt dişlerinde yapılmış herhangi bir çalışma bulunmamaktadır.

\section{Reciproc}

Tek eğe sistemi ile kanalların şekillendirilmesine olanak sağlayan Reciproc sistemi eğeleri; Ni-Ti alaşımın ısıl işlem operasyonuna maruz bırakılmasıyla üretilmektedir. Bu eğeler azalmış elastiklik modülleri ve döngüsel yorgunluğa karşı yüksek dirençleri ile dikkat çekmektedirler. ${ }^{68,69}$ Aletin S şekilli çapraz kesit dizaynları iki adet etkili kesici bıçak tasarımına olanak sağlamıştır. Değiş̧ik boyutlarda ve taperłarda eğe sistemine sahiptirler. Amaral ve ark ${ }^{70}$ Reciproc, Wave One ve Mtwo döner aletlerini kullanarak, şekillendirme sırasında kaldırılan smear tabakası miktarını karşılaştırmışlardır. Koronal, orta ve apikal üçlüdeki smear tabakasını elektron mikroskobu ile ayrı ayrı değerlendirmişlerdir. Çalışma sonucunda; smear tabakasını kaldırmada özellikle koronal ve orta üçlüde üç sistemin de benzer ve etkili sonuç gösterdiği görülmüştür. Bu sistemle ilgili süt dişlerinde yapılmış bir çalışma bulunmamaktadır.

\section{Self-Adjusting File (SAF)}

Yeni geliştirilen enstrümantasyon ve irrigasyon sistemi olan Sef-Adjusting File (SAF), ReDent-Nova firması tarafından geliştirilmiştir. Mekanik preparasyon işlemi boyunca devamlı irigasyon yapan, delikli yapıda resiprokasyon hareketli alet sistemi ile çalışmaktadır. SAF kök kanalına girdiğinde, kendini kanalın uzun ve enine kesitine adapte eder. İçeri ve dışarı vibrasyon hareketi yapar ve kafes tellerin abraziv yüzeyi ile birlikte üniform dentin kaldırımasını destekler. ${ }^{71} \mathrm{De}$ Melo Ribeiro ve ark $^{72}$ yaptıkları çalışmada; 26 adet oval tek köklü alt kesici dişi iki gruba ayırarak, SAF ve $\mathrm{Ni}$-Ti döner alet sistemi ile şekillendirmişlerdir. Kök kanal şekillendirmesinden sonra örneklerin apikal üçülerindeki debris miktarı ve şekillendirilmemiş kanal duvarı yüzeyi optik mikroskopta analiz edilmiş- tir. Araştırmalarının sonucunda; kalan debris yüzdesi ve şekillendirilmemiş kanal duvarı yüzeyi SAF grubun- da döner alet grubuna oranla belirgin ölçüde düşük bulunmuştur. Yine SAF grubunda örneklerin çoğunda hiç debris bulunmazken, döner alet grubunda ise kanalların \%53'ünde debris varlığı tespit edilmiştir. Self adjusting file sistemiyle ilgili literatürde süt dişlerinde yapılmış çalışma bulunmamaktadır.

\section{SONUÇ}

Süt dişi kanal tedavisinde döner alet sistemlerinin kullanılması; doku ve debrisin daha etkili ve hızı uzaklaştırıması, kanallara girişin daha kolay sağlanması ve daha etkili bir kanal dolgusuna izin veren konik şekilli kanalların elde edilmesi gibi avantajlar sağlamaktadır. Ayrıca preparasyon işleminin çocuklarda daha kısa sürede bitirilmesine ve koronal kısmın ilk aşamada genişletilmesi ile dezenfektanların etkili kullanımına olanak vermektedir. Geçmişte çoklu eğe grubu içeren Nikel-Titanyum döner aletlerin süt dişlerinde kullanımı ile ilgili az sayıda çalışma yapılmıştır. Çalışmalar daha çok daimi dişler üzerinde yoğunlaşmaktadır. Tek eğe sistemleri ise kullanım açısından hekime zaman kazancı sağlamakta ve özellikle çocuk hastalarda daha etkili olabilmektedir. Süt dişlerinde, tek eğe sistemleri ile kök kanal şekillendirmesi sonucunda oluşabilecek komplikasyonlarla ilgili ayrıntılı çalışmalara intiyaç duyulmaktadır.

\section{KAYNAKLAR}

1. Doğan SK, Doğan C, Yoldaş O. Süt dişlerinde paramolar kanalların görülme sıklığının araştırılması. Atatürk Üniv Diş Hek Fak Derg 2006; 16: 23-6.

2. Güler Ç, Gürbüz T, Yılmaz Y. İki farkli kök kanal şekillendirme yöntemi, irrigasyon solüsyonu ve dolgu maddesi kullanilarak kök kanal tedavisi yapilan çocuklarda gingival kriterlerin değerlendirilmesi. Atatürk Üniv Diş Hek Fak Derg 2009; 19: 168-76.

3. Bodur $\mathrm{H}$, Odabas $\mathrm{M}$, Tulunoglu $\mathrm{O}$, Tinaz AC. Accuracy of two different apex locators in primary teeth with and without root resorption. Clin Oral Investig 2008; 12: 137-41.

4. Leonardo MR, Silva LA, Nelson-Filho P, Silva RA, Raffaini MS. Ex vivo evaluation of the accuracy of two electronic apex locators during root canal length determination in primary teeth. Int Endod J 2008; 41: 317-21.

5. Kalra N, Sushma K, Mahapatra GK. Changes in developing succedaneous teeth as a consequence of infected deciduous molars. J Indian Soc Pedod

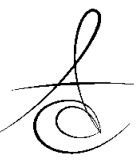


Prev Dent 2000; 18: 90-4.

6. Cordeiro MM, Rocha MJ. The effects of periradicular inflamation and infection on a primary tooth and permanent successor. J Clin Pediatr Dent 2005; 29: 193-200.

7. Kummer TR, Calvo MC, Cordeiro MM, de Sousa Vieira R, de Carvalho Rocha MJ. Ex vivo study of manual and rotary instrumentation techniques in human primary teeth. Oral Surg Oral Med Oral Pathol Oral Radiol Endod 2008; 105: 84-92.

8. da Silva LA, Nelson-Filho P, Faria G, de SouzaGugelmin MC, Ito IY. Bacterial profile in primary teeth with necrotic pulp and periapical lesions. Braz Dent J 2006; 17: 144-8.

9. Pinheiro $S L$, Schenka $A A$, Neto $A A$, de Souza $C P$, Rodriguez HM, Ribeiro MC. Photodynamic therapy in endodontic treatment of deciduous teeth. Lasers Med Sci 2009; 24: 521-6.

10. Moskovitz M, Yahav D, Tickotsky N, Holan G. Long-term follow up of root canal treated primary molars. Int J Paediatr Dent 2010; 20: 207-13.

11. Nagaratna PJ, Shashikiran ND, Subbareddy VV. In vitro comparison of NiTi rotary instruments and stainless steel hand instruments in root canal preparations of primary and permanent molar. J Indian Soc Pedod Prev Dent 2006; 24: 186-91.

12. Sari S, Ozalp N, Ozer L. The effect of formocresol on bond strength of adhesive materials to primary dentine. J Oral Rehabil 2004; 31: 671-4.

13. Çalışkan K. Kanal aletleri ve kök kanal genişletme yöntemleri. Çallşkan K, editor. İstanbul: Nobel Tıp Kitabevleri; 2006. p.276-8

14. Dafalla AA, Hassan Abubakr N, Ibrahim EY. An in vitro comparison of root canal system prepared with either hand or rotary instruments. Iran Endod J 2010; 5: 167-73.

15. Tepel J, Schafer E, Hoppe W. Properties of endodontic hand instruments used in rotary motion. Part 3. Resistance to bending and fracture. J Endod 1997; 23: 141-5.

16. Silva LA, Leonardo MR, Nelson-Filho P, Tanomaru JM. Comparison of rotary and manual instrumentation techniques on cleaning capacity and instrumentation time in deciduous molars. J Dent Child (Chic) 2004; 71: 45-7.

17. Nazari Moghaddam K, Mehran M, Farajian Zadeh $\mathrm{H}$. Root canal cleaning efficacy of rotary and hand files instrumentation in primary molars. Iran Endod J 2009; 4: 53-7.

18. Barr ES, Kleier DJ, Barr NV. Use of nickel-titanium rotary files for root canal preparation in primary teeth. Pediatr Dent 2000; 22: 77-8.

19. Crespo S, Cortes O, Garcia C, Perez L. Comparison between rotary and manual instrumentation in primary teeth. J Clin Pediatr Dent 2008; 32: 295-8.

20. Soares $F$, Varella $\mathrm{CH}$, Pileggi $\mathrm{R}$, Adewumi $A$, Guelmann M. Impact of Er,Cr:YSGG laser therapy on the cleanliness of the root canal walls of primary teeth. J Endod 2008; 34: 474-7.

21. Guelzow A, Stamm O, Martus P, Kielbassa AM. Comparative study of six rotary nickel-titanium systems and hand instrumentation for root canal preparation. Int Endod J 2005; 38: 743-52.

22. Foschi F, Nucci C, Montebugnoli L, Marchionni S, Breschi L, Malagnino VA, et al. SEM evaluation of canal wall dentine following use of Mtwo and ProTaper NiTi rotary instruments. Int Endod J 2004; 37: 832-9.

23. Veltri $M$, Mollo $A$, Mantovani $L$, Pini $P$, Balleri $P$, Grandini S. A comparative study of EndoflareHero Shaper and Mtwo NiTi instruments in the preparation of curved root canals. Int Endod J 2005; 38: 610-6.

24. Tasdemir T, Ceyhanlı T. Üç farkli döner alet tekniğinin apikalden itilen yikama solüsyonu ve debris yönünden karşılaştırıması. Atatürk Üniv Diş Hek Fak Derg 2006; 16: 33-6.

25. Barr ES, Kleier DJ, Barr NV. Use of nickel-titanium rotary files for root canal preparation in primary teeth. Pediatr Dent 1999; 21: 453-4.

26. Siqueira JF, Jr., Araujo MC, Garcia PF, Fraga RC, Dantas CJ. Histological evaluation of the effectiveness of five instrumentation techniques for cleaning the apical third of root canals. J Endod 1997; 23: 499-502.

27. Esposito PT, Cunningham CJ. A comparison of canal preparation with nickel-titanium and stainless steel instruments. J Endod 1995; 21: 173-6.

28. Short JA, Morgan LA, Baumgartner JC. A comparison of canal centering ability of four instrumentation techniques. J Endod 1997; 23: 503-7.

29. Thompson SA, Dummer PM. Shaping ability of ProFile.04 Taper Series 29 rotary nickel-titanium instruments in simulated root canals. Part 2. Int Endod J 1997; 30: 8-15.

30. Ferraz CC, Gomes NV, Gomes BP, Zaia AA, Teixeira FB, Souza-Filho FJ. Apical extrusion of 
debris and irrigants using two hand and three engine-driven instrumentation techniques. Int Endod J 2001; 34: 354-8.

31. Bonaccorso A, Tripi TR, Rondelli G, Condorelli GG, Cantatore G, Schafer E. Pitting corrosion resistance of nickel-titanium rotary instruments with different surface treatments in seventeen percent ethylenediaminetetraacetic Acid and sodium chloride solutions. J Endod 2008; 34: 208-11.

32. Yared GM, Bou Dagher FE, Machtou P. Cyclic fatigue of ProFile rotary instruments after clinical use. Int Endod J 2000; 33: 204-7.

33. Küçükay S, Küçükay I, Yılmaz B. Kök Kanalı Şekillendirme Yöntemleri. Küçükay $S$, editor. İstanbul: Promat AŞ; 2004.p.90-95.

34. Arikan V, Sari S, M. A, A.E. Z. Sut disi kok kanal tedavisinde Hero 642 Protaper $\mathrm{Ni}-\mathrm{Ti}$ doner sistemler ve $\mathrm{K}$ tipi egenin preparasyon guvenligi ve suresi acısından in-vitro olarak karsılastırılması Ankara Üniv Diş Hek Fak Derg 2010; 37: 89-96.

35. Hulsmann M, Schade M, Schafers F. A comparative study of root canal preparation with HERO 642 and Quantec SC rotary Ni-Ti instruments. Int Endod J 2001; 34: 538-46.

36. Bahcall JK, Barss JT. Understanding and evaluating the endodontic file. Gen Dent 2000; 48: 690-2.

37. Pettiette MT, Metzger Z, Phillips C, Trope M. Endodontic complications of root canal therapy performed by dental students with stainless-steel K-files and nickel-titanium hand files. J Endod 1999; 25: 230-34.

38. Seraj B, Ramezani G, Ghadimi S, Mosharrafian SH, Motahhary $P$, Safari $M$. In-vitro comparison of instrumentation time and cleaning capacity between endodontic handpiece and manual preparation techniques in primary molar teeth. Minerva Stomatol 2013; 62: 17-22.

39. Canoglu H, Tekcicek MU, Cehreli ZC. Comparison of conventional, rotary, and ultrasonic preparation, different final irrigation regimens, and 2 sealers in primary molar root canal therapy. Pediatr Dent 2006; 28: 518-23.

40. Kaptan F, Sert S, Kayahan B, Haznedaroglu F, Tanalp J, Bayirli G. Comparative evaluation of the preparation efficacies of HERO Shaper and Nitiflex root canal instruments in curved root canals. Oral Surg Oral Med Oral Pathol Oral Radiol Endod 2005; 100: 636-42.

41. Musale PK, Mujawar SA. Evaluation of the efficacy of rotary and hand files in root canal preparation of primary teeth in vitro using CBCT. Eur Arch Paediatr Dent 2014; 15: 113-20.

42. Schafer E, Erler M, Dammaschke T. Comparative study on the shaping ability and cleaning efficiency of rotary Mtwo instruments. Part 1. Shaping ability in simulated curved canals. Int Endod J 2006; 39: 196-202.

43. Schafer E, Erler M, Dammaschke T. Comparative study on the shaping ability and cleaning efficiency of rotary Mtwo instruments. Part 2. Cleaning effectiveness and shaping ability in severely curved root canals of extracted teeth. Int Endod J 2006; 39: 203-12.

44. Kuzekanani M, Walsh $\sqcup$, Yousefi MA. Cleaning and shaping curved root canals: Mtwo vs ProTaper instruments, a lab comparison. Indian J Dent Res 2009; 20: 268-70.

45. Sonntag D, Ott M, Kook K, Stachniss V. Root canal preparation with the NiTi systems K3, Mtwo and ProTaper. Aust Endod J 2007; 33: 73-81.

46. Azar MR, Mokhtare M. Rotary Mtwo system versus manual $\mathrm{K}$-file instruments: efficacy in preparing primary and permanent molar root canals. Indian J Dent Res 2011; 22: 363.

47. Bonetti Filho I, Miranda Esberard R, de Toledo Leonardo R, del Rio CE. Microscopic evaluation of three endodontic files pre and post instrumentation. J Endod 1998; 24: 461-4.

48. Kazemi RB, Stenman E, Spangberg LS. Machining efficiency and wear resistance of nickel-titanium endodontic files. Oral Surg Oral Med Oral Pathol Oral Radiol Endod 1996; 81: 596-602.

49. Mounce RE. The K3 rotary nickel-titanium file system. Dent Clin North Am 2004; 48: 137-57.

50. Kum KY, Kazemi RB, Cha BY, Zhu Q. Smear layer production of $\mathrm{K} 3$ and ProFile $\mathrm{Ni}-\mathrm{Ti}$ rotary instruments in curved root canals: a comparative SEM study. Oral Surg Oral Med Oral Pathol Oral Radiol Endod 2006; 101: 536-41.

51. Gonzalez-Rodrguez MP, Ferrer-Luque CM. A comparison of Profile, Hero 642, and K3 instrumentation systems in teeth using digital imaging analysis. Oral Surg Oral Med Oral Pathol Oral Radiol Endod 2004; 97: 112-5.

52. Bergmans L, Van Cleynenbreugel J, Wevers M, Lambrechts $P$. Mechanical root canal preparation with $\mathrm{NiTi}$ rotary instruments: rationale, performance and safety. Status report for the American Journal of Dentistry. Am J Dent 2001; 14: 324-33. 
53. Schirrmeister JF, Strohl C, Altenburger MJ, Wrbas KT, Hellwig E. Shaping ability and safety of five different rotary nickel-titanium instruments compared with stainless steel hand instrumentation in simulated curved root canals. Oral Surg Oral Med Oral Pathol Oral Radiol Endod 2006; 101: 807-13.

54. Calberson FL, Deroose CA, Hommez GM, De Moor RJ. Shaping ability of ProTaper nickel-titanium files in simulated resin root canals. Int Endod J 2004; 37: 613-23.

55. Clauder T, Baumann MA. ProTaper NT system. Dent Clin North Am 2004; 48: 87-111.

56. Giovannone T, Migliau G, Bedini R, Ferrari M, Gallottini L. Shaping outcomes using two Ni-Ti rotary instruments in simulated canals. Minerva Stomatol 2008; 57: 143-54.

57. Gu YX, Zhu YQ, Du R. [A comparative study of three different rotary nickel titanium systems in the preparation of curved molar canals]. Shanghai Kou Qiang Yi Xue 2009; 18: 147-51.

58. Yun HH, Kim SK. A comparison of the shaping abilities of 4 nickel-titanium rotary instruments in simulated root canals. Oral Surg Oral Med Oral Pathol Oral Radiol Endod 2003; 95: 228-33.

59. Yoshimine $Y$, Ono M, Akamine A. The shaping effects of three nickel-titanium rotary instruments in simulated S-shaped canals. J Endod 2005; 31: 373-5.

60. Kuo C.I WYL, Chang H.H, Huang G.F, Lin C.P, Guo M.K, Li U.M. Application of $\mathrm{Ni}-\mathrm{Ti}$ rotary files for pulpectomy in primary molars. J Dentistry Sci 2006; 1: 10-5.

61. Yared G. Canal preparation using only one $\mathrm{Ni}-\mathrm{Ti}$ rotary instrument: preliminary observations. Int Endod J 2008; 41: 339-44.

62. Pedulla E, Grande NM, Plotino G, Palermo F, Gambarini G, Rapisarda E. Cyclic fatigue resistance of two reciprocating nickel-titanium instruments after immersion in sodium hypochlorite. Int Endod J 2013; 46: 155-9.

63. Plotino G, Grande NM, Testarelli L, Gambarini G. Cyclic fatigue of Reciproc and WaveOne reciprocating instruments. Int Endod J 2012; 45: 614-8.

64. Johnson E, Lloyd A, Kuttler S, Namerow K. Comparison between a novel nickel-titanium alloy and 508 nitinol on the cyclic fatigue life of ProFile 25/.04 rotary instruments. J Endod 2008; 34: 1406-9.
65. Webber J, Machtou P, Pertot W, Kuttler S, Ruddle C, West J. The WaveOne single reciprocating file system. Roots 2011; 1: 28-33.

66. Yoo YS, Cho YB. A comparison of the shaping ability of reciprocating $\mathrm{NiTi}$ instruments in simulated curved canals. Restor Dent Endod 2012; 37: 220-7.

67. Dhingra A, Kochar R, Banerjee S, Srivastava P. Comparative evaluation of the canal curvature modifications after instrumentation with One Shape rotary and Wave One reciprocating files. J Conserv Dent 2014; 17: 138-41.

68. De-Deus G, Brandao MC, Barino B, Di Giorgi K, Fidel RA, Luna AS. Assessment of apically extruded debris produced by the single-file ProTaper F2 technique under reciprocating movement. Oral Surg Oral Med Oral Pathol Oral Radiol Endod 2010; 110: 390-4.

69. Varela-Patino P, Ibanez-Parraga A, RivasMundina B, Cantatore G, Otero XL, MartinBiedma B. Alternating versus continuous rotation: a comparative study of the effect on instrument life. J Endod 2010; 36: 157-9.

70. Amaral P, Forner L, Llena C. Smear layer removal in canals shaped with reciprocating rotary systems. J Clin Exp Dent 2013; 5: 227-30.

71. Metzger Z, Teperovich E, Zary R, Cohen R, Hof R. The self-adjusting file (SAF). Part 1: respecting the root canal anatomy--a new concept of endodontic files and its implementation. J Endod 2010; 36: 679-90.

72. de Melo Ribeiro MV, Silva-Sousa YT, Versiani MA, Lamira A, Steier L, Pecora JD, et al. Comparison of the cleaning efficacy of self-adjusting file and rotary systems in the apical third of oval-shaped canals. J Endod 2013; 39: 398-401.

\section{Yazışma Adresi}

Yrd. Doç. Dr. Bilge Gülsüm NUR

Şifa Üniversitesi, Diş Hekimliği Fakültesi, Pedodonti Anabilim Dalı

Mansuroğlu Mah. 293/1 Sk. No:2, 35100,

Bayraklı, İzmir/Türkiye

Tel: +90 2323080000 , Fax: +90 232

4864147

E-mail: dt.bilgenur@hotmail.com 